\title{
sciendo
}

\section{Relative Age Effect and Long-Term Success in the Spanish Soccer and Basketball National Teams}

\author{
by \\ Cristina López de Subijana ${ }^{1}$, Jorge Lorenzo ${ }^{1}$
}

\begin{abstract}
The aims of this study were: i) to analyze whether relative age effect occurs in the athletes of the junior national teams and professional athletes in Spain in general and in soccer and basketball, and ii) to compare the long-term success of the players selected for the junior national team between these sports. The samples for this study were Spanish professional soccer $(n=461)$ and basketball $(n=250)$ players in the 2013-2014 premier league and players from the junior Spanish soccer (i.e., $n=273 ; U-17: n=107 ; U-19: n=166$ ) and basketball (i.e., $n=240 ; U-18: n=120$, U-16: $n=120$ ) teams that classified to play in the European Championships (from 2004 to 2013). Junior players $(42.3 \%)$ were more frequently born in the 1st quarter of the year than the professional players $(30.7 \%)(\chi 2(3)=30.07$; $\left.p=.001 ; V_{c}=.157\right)$. This was found in both basketball $\left(\chi 2(3)=12.2 . ; p=.007 ; V_{c}=.158\right)$ and $\operatorname{soccer}(\chi 2(3)=20.13 ; p$ $\left.<.001 ; V_{c}=.166\right)$. Long-term success is more frequent in soccer, where $59.9 \%$ of the juniors selected for the national team played later in the premier league, while in basketball that percentage was $39.6 \%\left(\chi 2(1)=14.64 ; p<.001 ; V_{c}=\right.$ .201). On the other hand, $79.4 \%$ and $39.8 \%$ of the professional soccer and basketball players had been previously selected for junior national teams $(\chi 2(1)=60.2 ; p<.001 ; V c=.386)$, respectively. The talent selection process should be reviewed as players born in the second half of the year have fewer opportunities to stand out.
\end{abstract}

Key words: talent, selection, performance, soccer, basketball.

\section{Introduction}

Youth sport competitions are organized by the age category. Theoretically, this criterion should assure parity in maturation among the participants. However, when distributing the athletes in groups by age, physical (Delorme and Raspaud, 2009, Delorme et al., 2010a; Delorme et al., 2011), cognitive (Bisanz et al., 1995), and motivational (Dixon et al., 2011) differences are ignored. The athletes born at the end of the year are at a disadvantage compared to those born at the beginning of the year (Helsen et al., 2005; Schorer et al., 2009, 2011; Sherar et al., 2007). Moreover, most of the sports include two consecutive years in one category, thus differences are even greater among the players (Gil et al., 2014).

The term "relative age" refers to a person's age relative to his/her peers who were born in the same calendar year (Gil et al., 2014). The consequence of the variations in age within one annual cohort is known as the relative age effect (RAE) (Wattie et al., 2008). RAE has been studied in depth in most team sports, such as hockey (Nolan and Howell, 2010), soccer (Gil et al., 2007, 2014; Helsen et al., 2005; Williams, 2010; Romann and Fuchslocher, 2013), basketball (Delorme and Raspaud, 2009; Torres-Unda et al., 2013; García et al., 2014, 2015; Nakata and Sakamoto, 2011), rugby (Till et al., 2009), and volleyball (Nakata and Sakamoto, 2011).

These previous studies demonstrate that there is an overrepresentation of athletes born in the first quarter of the year (Helsen et al., 2005; Musch and Grondin, 2001; Wattie et al., 2007). Athletes born at the beginning of the year can take advantage of their own physical development;

1 - Sport Sciences Faculty, Universidad Politécnica de Madrid, Av. Martín Fierro, 7. 28040 Madrid, Spain. 
therefore, they have a better chance of being selected for the national team in their category (Cobley et al., 2009; Musch and Grondin, 2001; Sherar et al., 2007; Torres-Unda et al., 2013). This selection process could give these athletes more chances of success because of the quality of training and competition (Gladwell, 2008), as well as significantly increase their visibility. In addition, both intrinsic and extrinsic motivation could produce these results. Dixon et al. (2011) claimed that most children that matured early demonstrated better motor coordination and were at the top of the rankings in individual sports, leaving behind those athletes that developed later. Furthermore, the athletes that develop earlier than the rest in their age group and are selected for the national team enjoy more hours of deliberate practice compared to those who are not selected (Lorenzo and Sampaio, 2005).

Nevertheless, when performance is analyzed relative to the time on the court, the differences between the age groups are not maintained (Arrieta et al., 2016). Therefore, one of the negative consequences of RAE is the premature dropout of the players born during the second half of the year, because they become unmotivated as they are not selected for the teams. In a study conducted with youth basketball categories in France, the dropout was more frequent among the players born in the last two quarters of the year (Delorme et al., 2011).

Moreover, recent studies show that RAE increases from younger youth categories to adolescence (Del Campo et al., 2010; Muller et al., 2015). In a study conducted by Delorme et al. (2010b), the age ranges where RAE was found in French soccer players was from 7 to 18 years of age. On the other hand, Arrieta el al. (2016) analyzed U-16, U-18, and U-20 basketball players, and found RAE in U-20 when growth had finished. However, Werneck et al. (2016) found a uniform distribution of birth dates in a study of Olympic basketball players.

It seems that RAE is more frequent in high-level sport environments, such as national or professional clubs' junior teams. Mujika et al. (2009) found higher odds ratios in elite youth soccer players when compared to the general population than in regional or school soccer players. Also, Praxédes et al. (2017) in a study with 1,098 youth soccer players found that RAE was more frequent among the teams selected as A (best one of the club in their category) or B (second on performance) rather than in the other $\mathrm{C}$ to $\mathrm{G}$ teams. Along the same lines, Wattie et al. (2009) did not find RAE in recreational soccer players. Moreover, two studies conducted in professional soccer and basketball leagues in Spain showed RAE in both sports (Esteva et al., 2006; Lesma et al., 2011).

This initial physical advantage can hide or compensate for technical or tactical deficiencies that are present in most team sports (Regnier et al., 1992), and it may result in erroneously selecting national team players based on physical development as opposed to technical and tactical qualities. In fact, this effect has been clearly established in individual sports, but it is not so clear in team sports. Kirkendall (2014) showed that soccer players selected according to their physical advantage within their age group did not affect the outcome of the game or even the final ranking. On the other hand, Arrieta et al. (2016) found that RAE was strongly associated with the success of the teams in the U-20 European Basketball Championships.

In Spain, soccer and basketball national teams have had great success in both junior and senior age groups. Over the last decade, they have won World and European Championships (basketball) and Cups (soccer). This high performance at early stages may act against the long-term interest of the players (Henry, 2013), because players born at the beginning of the year may not realize their expectations in the future when they try to reach the professional level. On the other hand, players born in the second half of the year may dropout in adolescence, despite the fact that they could become great professional players. Long-term planning should be a priority of sport federations in order to provide equal opportunities to all players at their development stage.

To date, no RAE analysis has been carried out considering junior national teams or Spanish players in professional leagues, and no study has been performed focused on junior players that reach the professional level. Therefore, the aims of this study were: i) to analyze whether RAE occurs among the athletes of the junior national teams and professional athletes in Spain in general and in soccer and basketball, and ii) to compare the 
long-term success of the players selected for the junior national team between these sports.

\section{Methods}

\section{Participants}

The sample of this study consisted of the entire population of Spain's professional soccer (n $=461)$ and basketball $(n=250)$ players from the 2013-2014 premier league and players from Spain's junior teams who classified to play in the European Championships from 2004 to 2013. There were 273 junior soccer (i.e., $\mathrm{U}-17: \mathrm{n}=107$; $\mathrm{U}$ 19: $\mathrm{n}=166$ ) and 240 junior basketball (i.e., U-18: $\mathrm{n}$ $=120, \mathrm{U}-16: \mathrm{n}=120$ ) players.

\section{Design and Procedures}

Data were gathered from the official websites of the premier leagues (http://www.ligabbva.com/ for soccer and http://www.acb.com/ for basketball), from the official European Championships websites, and from the national federation websites (http://www.rfef.es/ for soccer and http://www.feb.es/index.aspx for basketball). Data were verified on the club's official web page for each player. To analyze whether RAE occurred among the athletes of the junior national teams and professional athletes in Spain in general and in soccer and basketball, the athlete's birth date was categorized according to the four quarters of the year (1st Quarter = January, February, and March; 2nd Quarter = April, May, and June; 3rd Quarter $=$ July, August, and September; and 4th Quarter $=$ October, November, and December). In order to compare the long-term success of the players selected for the junior national teams between soccer and basketball, two variables were taken into consideration. The first was whether the junior players had reached the professional level (yes/no). The second was whether the professional players had ever been on the national team in the junior categories (yes/no).

\section{Data Analysis}

A database was created to analyze the data with SPPS v.20 (Statistical Package for Social Sciences). Percentages were calculated for the descriptive analysis. A Pearson's chi-square test was applied for all comparisons between groups. The birth quarter was compared between junior and professional players in general and for each sport separately. Whether a professional player was ever selected for the junior team or a junior player ever reached the professional level was analyzed by sport. Cramer's V (Cv) was used as an effect size indicator. In line with other studies (Cohen, 1988), $\mathrm{Cv}=0.10$ was considered to be a small effect, $\mathrm{Cv}=0.30$ was considered a medium effect, and $\mathrm{Cv}=0.50$ was considered a large effect. Significance was set at 05 .

\section{Results}

Relationships between the birth date and the level of the competition were assessed $(\chi 2(3)=$ 30.07; $\mathrm{p}=.001 ; \mathrm{Vc}=.157$ ) (Table 1). First quarter birth dates were more frequent $(42.3 \%)$ among junior players than among professional players $(30.7 \%)$. On the other hand, 4 th quarter birthdates were more frequent among professional players $(18.0 \%)$ than for junior level players $(9.2 \%)$. This pattern was found in basketball $(\chi 2(3)=12.2$; $p=$ $.007 ; \mathrm{Vc}=.156)$ and soccer $(\chi 2(3)=20.13 ; p<.001$; $\mathrm{Vc}=.166)($ Table 1).

In the analysis of the long-term success of the selection criteria for the junior national team (as measured by the proportion of junior players reaching the professional level), there were differences between the two sports (Tables 2 and 3). In the prospective analysis, $59.9 \%$ of the junior soccer players selected for the national team played later in the premier league, while in basketball, that percentage was $39.6 \%(\chi 2(1)=$ 14.64; $p<.001 ; \mathrm{Vc}_{\mathrm{c}}=.201$ ).

In the retrospective analysis, which took into consideration whether the Spanish professional players were ever selected for the national team at the junior level, $79.4 \%$ of the professional soccer players had been previously selected for junior national teams, while $39.8 \%$ of basketball players had likewise been previously selected $\left(\chi 2(1)=60.2 ; p<.001 ; \mathrm{Vc}_{\mathrm{c}}=.386\right)$.

\section{Discussion}

The results of this study show that in relation to the first aim, RAE occurs at the junior level in basketball and soccer. This overrepresentation of the first half of the year is not maintained at the professional level. In relation to the second aim, long-term planning seems to be more successful in soccer than in basketball. In soccer, players selected for the national team in junior categories reach the professional level more frequently than in basketball. 
Table 1

Birth quarter relative to the level of competition (professionalljunior) and sport.

\begin{tabular}{|c|c|c|c|c|c|c|c|c|c|c|c|c|}
\hline & \multicolumn{4}{|c|}{ Basketball* $^{*}$} & \multicolumn{4}{|c|}{ Soccer ${ }^{* *}$} & \multicolumn{4}{|c|}{ Total $^{*}$} \\
\hline & \multicolumn{2}{|c|}{ Professional } & \multicolumn{2}{|c|}{ Junior } & \multicolumn{2}{|c|}{ Professional } & \multicolumn{2}{|c|}{ Junior } & \multicolumn{2}{|c|}{ Professional } & \multicolumn{2}{|c|}{ Junior } \\
\hline & $\%$ & $\mathrm{~N}$ & $\%$ & $\mathrm{~N}$ & $\%$ & $\mathrm{~N}$ & $\%$ & $\mathrm{~N}$ & $\%$ & $\mathrm{~N}$ & $\%$ & $\mathrm{~N}$ \\
\hline $1^{\text {st }}$ & 29.6 & 74 & 38.3 & 92 & 31.2 & 144 & 45.8 & 125 & 30.7 & 218 & 42.3 & 217 \\
\hline $2^{\text {nd }}$ & 32.0 & 80 & 35.0 & 84 & 29.7 & 137 & 28.6 & 78 & 30.5 & 217 & 31.6 & 162 \\
\hline $3^{\text {rd }}$ & 19.6 & 49 & 17.9 & 43 & 21.5 & 99 & 16.1 & 44 & 20.8 & 148 & 17.0 & 87 \\
\hline $4^{\text {th }}$ & 18.8 & 47 & 8.8 & 21 & 17.6 & 81 & 9.5 & 26 & 18.0 & 128 & 9.2 & 47 \\
\hline
\end{tabular}

Note: Significant differences found regarding the birth quarter between professional and junior players ${ }^{* *} p<.001 ;{ }^{*} p<.01$.

Table 2

Junior national-team players that reached professional leagues.

\begin{tabular}{lcccccc}
\hline & \multicolumn{2}{c}{ Basketball } & \multicolumn{2}{c}{ Soccer } & \multicolumn{2}{c}{ Total } \\
\cline { 2 - 7 } & $\%$ & $\mathrm{~N}$ & $\%$ & $\mathrm{~N}$ & $\%$ & $\mathrm{~N}$ \\
\hline Yes & 39.6 & 63 & 59.9 & 121 & 51.0 & 184 \\
No & 60.4 & 96 & 40.1 & 81 & 49.0 & 177 \\
\hline
\end{tabular}

Note: Significant differences found regarding juniors reaching the professional level between sports ${ }^{* *} p<.001$.

Table 3

Professional players previously selected for junior national teams.

\begin{tabular}{lcccccc}
\hline & \multicolumn{2}{c}{ Basketball } & \multicolumn{2}{c}{ Soccer } & \multicolumn{2}{c}{ Total } \\
\cline { 2 - 7 } & $\%$ & $\mathrm{~N}$ & $\%$ & $\mathrm{~N}$ & $\%$ & $\mathrm{~N}$ \\
\hline Yes & 39.8 & 47 & 79.4 & 228 & 67.9 & 275 \\
No & 60.2 & 71 & 20.6 & 59 & 32.1 & 130 \\
\hline
\end{tabular}

Note: Significant differences found regarding professionals previously selected for junior national teams between sports ${ }^{* *} p<.001$. 
The results of this research show how RAE occurs in Spain at the junior level. Therefore, if a young athlete is born during the first quarter of the year he/she has a better chance of being selected for a junior national team. These results are in accordance with the findings of Williams (2010) where $40 \%$ of the European players in the U-17 Soccer World Cup were born in the first quarter of the year. In the European and World Basketball Championships of the U-16, U-18, and U 20 categories, García et al. (2014) and Arrieta et al. (2016) confirmed the existence of RAE in the national teams too. These results are consistent with RAE among basketball and soccer players in Spain's youth categories (Esteva et al., 2006; Gil et al., 2014).

Moreover, Del Campo et al. (2010) compared RAE in the Spanish Premier League for the U-11, U-13, U-15 and U-17 categories of 20 clubs during two seasons three years apart (20052006 and 2008-2009). They found that RAE was more common in youth categories. RAE in junior basketball teams was likewise confirmed by Torres-Unda et al. (2013). Consistent with those findings, our results demonstrate how professional players' birth dates are equally distributed in both sports. This could be explained by the theory of maturation (Malina et al., 2004; Philippaerts et al., 2006; Simmons and Paull, 2001), which postulates that the main criteria for choosing players from the first quarter of the year could be their greater anthropometric, cognitive, and physical development compared to the other players. In turn, belonging to a professional club is the key to being selected for the national team. Thus, this means that if a child is born in the first two quarters of the year, he or she is more likely to be selected in the youth categories of professional clubs, and therefore, his or her chances of being selected for the national team are also biased (Mujika et al., 2009).

$$
\text { Regarding long-term planning, }
$$

differences are found between these two sports. In soccer, players selected at the junior level have a good chance of reaching the professional level in the future. This pattern is not followed in basketball. In terms of selection criteria, the soccer federation relates future success with features of the young athletes, while the basketball federation does not. Along these lines, previous researchers have shown how RAE is not frequently found at the professional soccer level (Del Campo et al., 2010). Yet taking into consideration that most of the selected players are from the first quarter of the year, it should be mentioned that the relationship between the biological and chronological ages (height) is a key element in the selection criteria for junior players in basketball (Schorer et al., 2011). This importance placed on height decreases over time. By the senior category, RAE is almost non-existent (García et al., 2015). In terms of performance, when data are analyzed in relation to time on the court, no significant differences are found among players of different birth quarters (Gil et al., 2014). Thus, by the time biological growth no longer affects the game (senior-professional level), the player may have already quit the sport. Delorme et al. (2011) showed how quitting basketball at junior stages (from 11 to 17) was more frequent among players born in the last quarter of the year.

Therefore, selecting the junior national basketball players based on biological maturation, knowing that they may not reach the professional level, may lead to a negative RAE. With regard to the Spain's Basketball Federation, they may choose the short-term sport results rather than the basketball player's long-term future interest (Henry, 2013). Splitting the team into the "good" and "bad" players results in the "good" ones having more deliberate practice (i.e. playing time) and gaining more learning experience than the "bad" ones (Gladwell, 2008). But, in fact, RAE affects the opportunities that are provided to those who did not have the chance of being in the "selected" group.

The present study has some limitations. First of all, there may be other factors related to age that could bias the results that were not considered, such as economic and social status, or if the players studied or not during their sport career (Lupo et al., 2015), their sport experience, competitive behavior, the player's position during the game or a specific talent for the sport (Lesma et al., 2011). Secondly, the restricted time frame that was utilized for the analysis limits the external validity.

\section{Conclusions}

In summary, RAE exists at the junior level in the national teams, both in soccer and basketball. This fact may lead to those players 
born in the first quarter of the year having more chances to practice and compete. RAE has less influence at the professional level. The selection criteria used in soccer seem to be more successful as soccer players selected for the junior national team tend to reach the professional level more frequently than in basketball. The talent selection process should be reviewed as players born in the second half of the year have fewer opportunities to stand out.

\section{References}

Arrieta H, Torres-Unda J, Gil SM, Irazusta J. Relative age effect and performance in the U16, U18 and U20 European Basketball Championships. J Sports Sci, 2016; 34(16): 1530-1534

Bisanz J, Morrison FJ, Dunn M. Effects of age and schooling on the acquisition of elementary quantitative skills. Dev Psychol, 1995; 31(2): 221-236

Cobley S, Baker J, Wattie N, McKenna J. Annual age-grouping and athlete development: a meta-analytical review of relative age effects in sport. Sports Med, 2009 (Auckland, N.Z.); 39(3): 235-256

Cohen J. Statistical power analysis for the behavioral sciences (2nd ed.). Hillsdale, NJ: Lawrence Earlbaum Associates; 1998

Del Campo D, Pastor JC, González S, Contreras O. The relative age effect in youth soccer players from Spain. J Sports Sci Med, 2010; 9(2): 190-198

Delorme N, Boiché J, Raspaud M. Relative age and dropout in French male soccer. J Sports Sci, 2010; 28: 717722

Delorme N, Boiché J, Raspaud M. Relative age effect in elite sports: Methodological bias or real discrimination? Eur J Sport Sci, 2010; 10: 91-96

Delorme N, Chalabaev A, Raspaud M. Relative age is associated with sport dropout: evidence from youth categories of French basketball. Scand J Med Sci Sports, 2011; 21(1): 120-128

Delorme N, Raspaud M. The relative age effect in young French basketball players: a study on the whole population. Scand J Med Sci Sports, 2009; 19(2): 235-242

Dixon J, Horton S, Weir P. Relative Age Effects: Implications for Leadership Development. Int J Sport Society, 2011; 2(2): 1-15

Esteva S, Drobnic F, Puigdellivol J, Serratosa L, Chamorro M. Date of birth and success in professional basketball. Apunts Medicina del Deporte [Sport Med], 2006; 41(149): 25-30

García MS, Aguilar ÓG, Galatti L, Romero JF. Relative Age Effect at the FIBA world championships junior categories. Cuadernos de Psicología del Deporte [Sport Psychol], 2015; 15(3): 237-242

García MS, Aguilar, ÓG, Romero JJF, Lastra DF, Oliveira GE. Relative age effect in lower categories of international basketball. Int Rev Sociol Sport, 2014; 49(5): 526-535

Gil S, Ruiz F, Irazusta A, Gil J, Irazusta J. Selection of young soccer players in terms of anthropometric and physiological factors. J Sports Med Phys Fit, 2007; 47: 25-32

Gil SM, Badiola A, Bidaurrazaga-Letona I, Zabala-Lili J, Gravina L, Santos-Concejero J, Lekue JA., Granados C. Relationship between the relative age effect and anthropometry, maturity and performance in young soccer players. J Sports Sci, 2014; 32(5): 479-486

Gladwell M. The Story of Success. Little, Brown and Company: New York: NY; 2002

Helsen W, van Winckel J, Williams AM. The relative age effect in youth soccer across Europe. J Sports Sci, 2005; 23(6): 629-636

Henry I. Athlete Development, Athlete Rights and Athlete Welfare: A European Union Perspective. Int J Hist 
Sport, 2013; 30(4): 356-373

Kirkendall T. The relative age effect has no influence on match outcome in youth soccer. J Sport Health Sci, 2014; 3(4): 273-278

Lesma ML, Pérez-González B, Salinero JJ. Relative age effect (RAE) in the Spanish soccer league. J Sport Health Res, 2011; 3(1): 35-46

Lorenzo A, Sampaio J. Reflections of the factors that may constrain the development of high performance elite athletes. Apunts, Educación Física y Deportes [Phy Ed Sports], 2005; 80: 63-70

Lupo C, Guidotti F, Goncalves CE, Moreira L, Doupona Topic M, Bellardini H, Tonkonogi M, Allen C, Capranica L. Motivation Toward Dual-Career of European Student-Athletes. Eur J Sport Sci, 2015; 15(2): 151-160

Malina R, Bouchard C, Bar-Or O. Maturation and physical activity. Human Kinetics: Champaign, IL; 2004

Mujika I, Vaeyens R, Matthys SP, Santisteban J, Goiriena J, Philippaerts R. The relative age effect in a professional football club setting. J Sports Sci, 2009; 27: 1153-1158

Muller L, Hildebrandt C, Raschner C. The relative age effect and the influence on performance in Routh alpine racing. J Sports Sci Med, 2015; 14(1): 16-22

Musch J, Grondin S. Unequal competition as an impediment to personal development: a review of the relative age effect in sport. Dev Rev, 2001; 21(2): 147-167

Nakata H, Sakamoto K. Relative age effect in Japanese male athletes. Percept Mot Skills, 2011; 113(2): 570-574

Nolan JE, Howell G. Hockey success and birth date: The relative age effect revisited. Int Rev Sociol Sport, 2010; 45: 507-512

Philippaerts RM, Vaeyens R, Janssens M, Van Renterghem B, Matthys D, Craen R, Bourgois J, Vrijens J, Beunen G, Malina RM. The relationship between peak height velocity and physical performance in youth soccer players. J Sports Sci, 2006; 24(3): 221-230

Praxedes A, Moreno A, García-González L, Pizarro D, Del Villar F. The Relative Age Effect on soccer players in formative stages with different sport expertise levels. J Hum Kinet, (in press-2017)

Régnier G, Salmela J, Russell SJ. Talent detection and development in sport. In Singer RN, Murphey M, Tennant LK, editors. Handbook of Research on Sport Psychology. New York: McMillan, 290-313; 1993

Romann M, Fuchslocher J. Influences of player nationality, playing position and height on relative age effects at women'sunder-17 FIFA World Cup. J Sports Sci, 2013; 31(1): 32-40

Schorer J, Cobley S, Busch D, Brautigam H, Baker J. Influences of competition level, gender, player nationality, career stage and playing position on relative age effects. Scand J Med Sci Sports, 2009; 19(5): 720-730

Schorer J, Neumann J, Cobley S, Tietjens M, Baker J. Lingering effects of relative age in basketball players' post athletic career. Int J Sports Sci Coach, 2011; 6(1): 143-148

Sherar LB, Baxter-Jones A, Faulkner RA, Russell KW. Do physical maturity and birth date predict talent in male youth ice hockey players? J Sports Sci, 2007; 25(8): 879-886

Simmons C, Paull GC. Season of birth bias in association soccer. J Sports Sci, 2001; 19(9): 677-686

Till K, Cobley S, Wattie N, O'Hara J, Cooke C, Chapman C. The prevalence, influential factors and mechanisms of relative age effects in UK Rugby League. Scand J Med Sci Sports, 2009; 20: 320-329

Torres-Unda J, Zarrazquin I, Gil J, Ruiz F, Irazusta A., Kortajarena M, Seco J, Irazusta J. Anthropometric, physiological and maturational characteristics in selected elite and non-elite male adolescent basketball players. J Sports Sci, 2013; 31(2): 196-203

Wattie N, Baker J, Cobley S, Montelpare WJ. A historical examination of relative age effects in Canadian hockey players. Int J Sport Psy, 2007; 38(2): 178-186

Wattie N, Cobley S, Baker J. Towards a unified understanding of relative age effects. J Sports Sci, 2008; 26: 
1403-1409

Werneck FZ, Coelho EF, de Oliveira HZ, Ribeiro Júnior DB, Almas SP, de Lima JRP, Matta MO, Figueiredo AJ. Relative age effect in Olympic basketball athletes. Sci Sports, 2016; 31: 158-161

Williams JH. Relative age effect in youth soccer: analysis of the FIFA U17 World Cup competition. Scand J Med Sci Sports, 2010; 20(3): 502-508

\section{Corresponding author:}

\section{Cristina López de Subijana}

Social Research in Sport Group. Sport Sciences Faculty,

Universidad Politécnica de Madrid,

Av. Martín Fierro, 8. 28040 Madrid, Spain

Phone: 34913364131

Email: c.lopezdesubijana@upm.es 